\title{
Dendrimer-based nanoparticles in cancer chemotherapy and gene therapy
}

\author{
Lei Jiang ${ }^{1,2}$, Sensen Zhou ${ }^{1}$, Xiaoke Zhang ${ }^{1}$, Wei $\mathrm{Wu}^{1}$ and Xiqun Jiang ${ }^{*}$
}

\begin{abstract}
This review discusses recent studies on dendrimer-based nanoparticles in cancer chemotherapy and gene therapy. In order to achieve the high efficacy and low side effects of chemotherapy and gene therapy, it is essential to combine the unique features of dendrimers and the specific tumor microenvironment to target delivery and control release of therapeutic agents to tumor tissues and cells. Strategies to design the dendrimer-based delivery system in this review include non-modified dendrimers, dendrimer conjugates, assembled amphiphilic dendrimers, nanohybrid dendrimer carriers and dendrimers with inherent activity. In addition, specific functional groups on these dendrimers as stimuli-responsive system for targeting delivery and controlled release of therapeutic agents are discussed.
\end{abstract}

Keywords: dendrimer-based nanoparticles, cancer, chemotherapy, gene therapy

\section{INTRODUCTION}

Cancer has become the major diseases threatening human health [1]. Chemotherapy and gene therapy are the usual methods to combat cancer [2-5]. However, the serious side effects and individually versatile therapeutic response always limit their future application [6-9]. In particular, tumor microenvironment shows numerous unique properties compared with normal tissues, such as vascular abnormalities induced by the enhanced permeability and retention (EPR) effect, lower $\mathrm{pH}$, anoxia, abnormal expressions of specific proteases and receptors. Therefore, it is possible to design nanomedicine as specific drug delivery systems, which are based on passive targeting, active targeting (e.g., ligand-receptor interaction) or stimuli-responsiveness to target delivery and control the release of therapeutic agents to tumor tissues and cells, which result in high efficacy and low side effects [10-14].

Dendrimers are a category of synthetic macromolecules with highly branched, monodispersed and well-defined tree-like architecture. The commonly used dendrimers include poly(amidoamine) (PAMAM) [15,16], poly(prophylenimine) (PPI), poly(L-lysine) (PLL) [17], triazine dendrimer $[18,19]$, poly(ether imine) (PETIM) [20-22], carbosilane dendrimer [23], viologen dendrimer [24], and phosphorus dendrimer [25-27]. The functional nanoparticles (NPs) can be constructed based on the unique features of dendrimers for delivery of therapeutic agents [28-35]. The well-defined nanoscale size and dimensionality could be used to satisfy various applications, especially to enhance the tumor accumulation and penetration of the therapeutic agents for tumor treatment [36-38]. The abundant surface functional groups of dendrimers enable multivalent effect to enhance binding and cellular uptake by ligand/receptor recognition [39]; the globular architecture of dendrimers can mimic proteins to avoid immunogenicity and improve biocompatibility [40]. Dendrimers with rich terminal reactive groups and excellent solubility can be easily modified with multiple ligands for specific therapies [41]. And more importantly, the interior hydrophobic cavity of dendrimers can load poor solubility drugs via noncovalent interactions, while the surface functional groups can be conjugated with drugs by covalent bond [42-44]. The cationic groups on the surface of dendrimers also can condense nucleic acids into nano-vehicle for efficient gene delivery $[45,46]$. Therefore, dendrimer-based NPs

\footnotetext{
${ }^{1}$ MOE Key Laboratory of High Performance Polymer Materials and Technology, and Department of Polymer Science \& Engineering, College of Chemistry \& Chemical Engineering, Nanjing University, Nanjing 210093, China

${ }^{2}$ State Key Laboratory of Natural Medicines, Department of Pharmaceutics, China Pharmaceutical University, Nanjing 210009, China

*Corresponding author (email: jiangx@nju.edu.cn)
} 


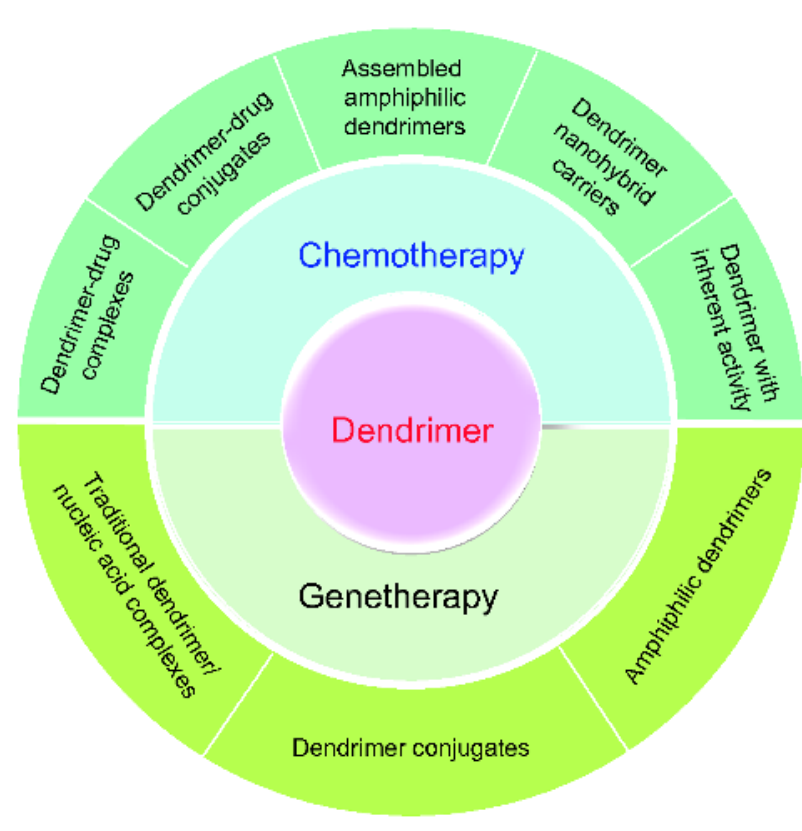

Scheme 1 A scheme showing the exploration of dendrimer-based NPs in cancer chemotherapy and gene therapy.

with the above properties are promising delivery systems for drugs and genes.

This review will introduce new strategies based on dendrimer-based NPs in cancer chemotherapy and gene therapy. Strategies adopted in the design of dendrimerbased delivery systems in this review include non-modified dendrimers, dendrimer conjugates, assembled amphiphilic dendrimers, nanohybrid dendrimer carriers and dendrimers with inherent activity, as shown in Scheme 1. Then we will discuss how to introduce specific functional groups onto these dendrimers as stimuli-responsive system for targeting delivery and controlled release of therapeutic agents.

\section{CHEMOTHERAPY}

To overcome disadvantages of the traditional chemotherapy, dendrimer-based NPs are often utilized for drug delivery. Drugs can be encapsulated in the interior cavities or conjugated on the surface of dendrimers via covalent linkages to improve drug solubility and functionalization. In the meantime, the nanoscale structure can enhance tumor accumulation and improve penetration capability of antitumor drugs [42-44,47,48].

\section{Dendrimer-drug complexes in chemotherapy}

Dendrimers contain highly branched internal cavities, which can be employed for loading hydrophobic drugs, forming dendrimer complexes to enhance their poor

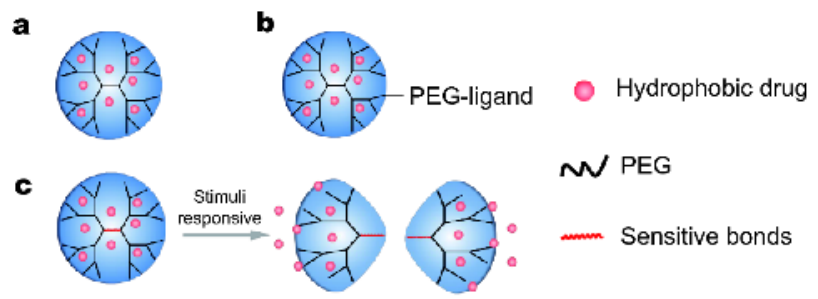

d

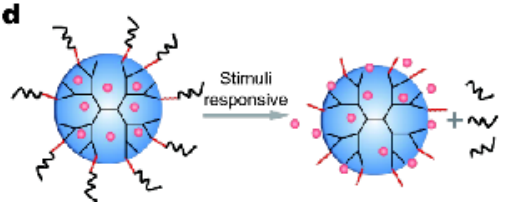

Figure 1 Dendrimer-drug complexes: (a) nonmodified dendrimersdrug complexes; (b) ligand modified PEGylated dendrimers-drug complexes; (c) sensitive bonds cross-linked dendrimers-drug complexes, (d) sensitive bonds as linker on dendrimers-drug complexes.

water solubility and enhance tumor tissue accumulation by EPR (Fig. 1a) [33,49,50]. To efficiently avoid the macrophage uptake and enhance accumulation in tumor tissue, dendrimer complexes modified with polyethylene glycol (PEG) linked ligands (such as PEG-folic acid, PEGiRGD and PEG-lactobionic acid) showed better antitumor effect than unmodified carriers (Fig. 1b) [51-53]. For improving drug release, dendrimer complexes with stimuli-responsive capacity can be built by introducing sensitive bonds into the dendrimer core (Fig. 1c) [54], or a spacer between dendrimer and shielding ligand (Fig. 1d) [55]. Besides, hydrophilic drugs also can be bonded onto the dendrimer surface to form dendrimer complexes via electrostatic interactions, hydrogen bond, and van der Waals interactions [56].

\section{Dendrimer-drug conjugates in chemotherapy}

Noncovalent encapsulation of drugs can hardly controll the release of payload from the dendrimer core, such as drug leakage in blood circulation, uncontrolled release rate, and so on [50]. Construction of dendrimer-drug conjugates with degradable linkages between the dendrimers and drug by stimuli-cleavable is a promising approach to control the release of drug. On the other hand, only few drugs can take effect without linkage broken [57-59]. Hydrazone bond is widely utilized for exploiting acid-responsive dendrimer-drug conjugates as prodrugs (Fig. 2a) [60-64]. The linkage is stable, and can resist hydrolysis in blood circulation ( $\mathrm{pH} 7.4)$, but degrades in tumor extracellular matrix $(\mathrm{pH}$ 6.5-6.8) and accelerates the release of drug after endocytosis into cancer cells ( $\mathrm{pH}$ 5.0-6.0). Recently, the boronate ester bond was also applied for developing acid-responsive 


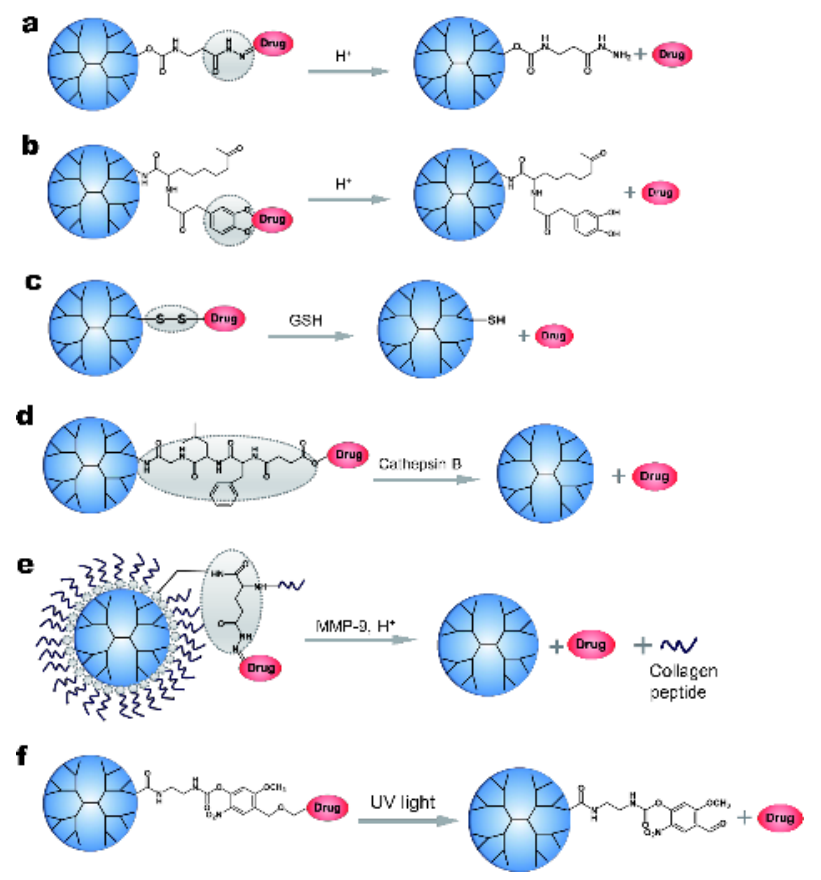

Figure 2 Dendrimer-drug conjugates: (a) dendrimer-drug conjugate by a hydrazone linkage; (b) dendrimer-drug conjugate by a boronate ester bond; (c) dendrimer-drug conjugate by disulfide bond; (d) dendrimerdrug conjugate via GFLG or (e) collagen peptide; (f) dendrimer-drug conjugate by light-responsive bonds.

prodrugs (Fig. 2b) [65,66], which was more sensitive under $\mathrm{pH} 6.5$ than hydrazone bond and induced fast drug release under tumor extracellular condition.

Disulfide bond was usually employed for development of reduction-responsive dendrimer-drug conjugates, which can be rapidly cleaved by abundant intracellular reduction agent glutathione (GSH) to release free drug [67-69]. In order to reduce the adverse effects and enhance the therapeutic index, doxorubicin and paclitaxel could be made into GSH-responsive dendrimer-drug conjugates as prodrugs (Fig. 2c). These dendrimer-drug conjugates show lower toxicity and higher efficacy, compared to free drugs by largely accumulation in tumor tissue [70-73].

Enzyme-labile bonds also could be employed for construction of enzyme-responsive prodrugs [74]. Proteases, such as matrix metalloproteinases (MMP) and cathepsin $\mathrm{B}$ are unusually expressed in the tumor microenvironment. Some specific sequences peptides can be cleaved by those over-expressed proteases, e.g., collagen peptide is cleavable by abundant MMP-9, and Gly-Phe-Leu-Gly oligopeptide (GFLG) is degradable in the presence of cathepsin B. When the specific peptide like GFLG (Fig. 2d) or collagen (Fig. 2e) is chosen as linkers to construct paclitaxel or doxorubicin prodrug, the specific therapy would be achieved by efficiently killing the cancer cells in tumor tissues and minimizing the toxicity to normal cells [75-77].

Light-labile bonds could be employed for light-responsive dendrimer-drug conjugates, which can be rapidly cleaved by external light trigger (e.g., ultraviolet (UV), visible or near-infrared (NIR)) to release free drug. Some specific linkers, such as orthonitrobenzyl (ONB), cleave under UV. The burst release of drugs happens in the presence of UV irradiation, when ONB is chosen as linker to conjugate the dendrimer and chemotherapeutics. These conjugates will minimize the toxicity on normal cells in the dark (Fig. 2f) [78,79].

\section{Assembled amphiphilic dendrimers in chemotherapy}

Self-assembly of amphiphilic molecules is one of the most commonly phenomena in biological systems $[80,81]$. Generally, amphiphilic dendrimers have two structural segments, the hydrophobic and hydrophilic components. Recently, self-assembly of amphiphilic dendrimers into nanocarriers is a promising approach to avoid disadvantages of dendrimer in cancer treatment, such as the uncontrolled drug release and serious toxicity of high generation dendrimers [82-84]. Particularly, well designed amphiphilic dendrimers could give the nano-vectors a series of special features in cancer therapy.

Wei and coworkers [85] reported a supramolecular nanomicellar carrier based on amphiphilic dendrimer (AmDM), which consisted of one small PAMAM dendrimer as hydrophilic part and two C18 alkyl chains as hydrophobic part. The resulting doxorubicin (DOX) loaded AmDM/DOX nanomicelles possess small size (about $10 \mathrm{~nm}$ ) and very high drug-loading ability (>40\%). AmDM/DOX drug delivery system can effectively improve anticancer efficiency and overcome drug resistance via the combination of enhanced cellular uptake and markedly reduced efflux of the drug. In addition, the AmDM/DOX nanocarriers significantly decrease systemic toxicity compared to the free DOX.

To achieve tumor-specific delivery of antitumor drug, acid-responsive amphiphilic dendrimers were designed. These amphiphilic dendrimers could self-assemble into nanocarriers, and the nanostructures could be disassembled to release drug under a changed hydrophiliclipophilic balance (HLB) in tumor tissue or organelle with specific acidic condition. This disassembly behavior could be triggered by protonation, deprotonation or cleavage of $\mathrm{pH}$-sensitive covalent bonds, such as ketal, boronate ester and hydrazone bonds [84,86-94]. Recently, an amide 
bond formed from 2-propionic-3-methylmaleic anhydride (CDM) was employed to develop newly acid-responsive amphiphilic dendrimers, which cleaved under tumor extracellular acid environment ( $\mathrm{pH} \sim 6.5-7.2)$ [95]. $\mathrm{Li}$ and coworkers [96] synthesized an amphiphilic dendrimer PCL-CDM-PAMAM/Pt and co-assembled with PEG-b-PCL and PCL to prepare pH-sensitive clustered NP (iCluster) by nanoprecipitation method. This iCluster could overcome systematically a series of barriers by sequentially reacting in the tumor microenvironment. At physiological $\mathrm{pH}$, iCluster hold a particle size about $100 \mathrm{~nm}$, which was helpful for long blood circulation and tumor tissue accumulation through the EPR effect. When iCluster heaps at tumor sites, the tumor extracellular acidic condition triggers the release of platinum prodrug PAMAM/Pt (diameter around $5 \mathrm{~nm}$ ) that greatly improves tumor penetration and cell internalization. The internalized PAMAM/Pt would be further reduced to release free cisplatin to eliminate cancer cells. The superior in vivo antitumor effect of iCluster also has been validated in various tumor models, which indicates this acid-responsive amphiphilic dendrimer facilitates overcoming systematically multilevel barriers to improve delivery efficacy and reduce adverse effects of drug.

Redox-responsive amphiphilic dendrimers based on disulfide bond are efficient drug carriers in tumor treatment. Shao and coworkers [97] proposed an amphiphilic dendrimer (named as telodendrimer), which was composed of dendritic polylysine, linear PEG and specific peripheral groups. Telodendrimer could self-assemble into nanocarriers and be disassembled via the responsiveness of the built-in disulfide cross-linker to the redox tumor microenvironment for controlled drug release and efficient drug delivery in vivo. Recently, Li and coworkers [98] designed lipoic acid (LA)-functionalized amphiphilic dendrons and PEG derivatives, which could self-assemble into supramolecular dendritic systems (TSPDSs) for efficient platinum delivery. This supramolecular dendritic system is able to stably exist by bio-reducible disulfide bonds and PEGylated platinum derivatives could coordinate with peripheral carboxyl of dendritic systems for tumor treatment. TSPDSs obviously improve the biodistribution and pharmacokinetics of platinum, due to the PEGylated shell and stable nanostructure in the blood circulation. High glutathione concentration of tumor intracellular environment could lead to the rapid disassembly of TSPDSs due to redox-cleavable disulfide bonds, and then platinum is transported into the nuclei to play antitumor role. Compared to clinical cisplatin, TSPDSs have higher antitumor efficiency and lower renal toxicity.

Enzyme-induced drug release via enzyme-sensitive chemical bond cleavage is a strategy to design enzymeresponsive NPs based on amphiphilic dendrimers for tumor therapy. A PEGylated amphiphilic peptide dendritic-drug conjugate is constructed via antitumor drug conjugated to the periphery of dendrimer by an enzymeresponsive linker and could self-assemble into enzymesensitive anti-cancer NPs. Owing to the on-off demand of drug and the nanoscale size, the in vivo antitumor efficacy of these enzyme-sensitive NPs is verified with reduced side effects [99-101]. Enzyme-responded hydrophilic-lipophilic balance (HLB) disruption is another strategy to construct enzyme-responsive materials. Amphiphilic dendrimer composed of enzyme-sensitive dendrons could self-assemble into nanocarriers that disassemble to release drug under action of enzymes [102].

Light-induced HLB disruption also is a strategy to design light-responsive amphiphilic dendrimers. Sun and coworkers [103] designed diazonaphthoquinone-modified amphiphilic PAMAM dendrimers, which could assemble into DNQ-cored micelles in aqueous solutions. Irradiated by NIR light, the micelles will produce an HLB change in the supermolecular system, which leads to the disassembly of the micelles and a quick release of the loaded DOX. The NIR-responsive amphiphilic dendrimer nanomedicine shows great potential for controlled drug delivery.

Multistimuli-responsive delivery system is a more effective strategy in drug delivery for combating tumor $[104,105]$. Li and coworkers [106] designed tumor-specific multistimuli-responsive nanoassemblies with a metabolic barrage to completely overcome both physiological and cellular barriers of multidrug resistance (Fig. 3). The nanoassemblies were self-assembled from amphiphilic dendrimers which consisted of tumor microenvironment MMP sensitive peptides (GPLGLAG sequence) to discharge hydrophilic PEG parts, cytoplasmic redox-labile disulfide bonds between peptide dendrons, and lysosome acid-breakage hydrazone bonds for linking antitumor drugs DOX. Impressively, the nanoassemblies could hierarchically overcome the serial barriers of drug resistance, including PEGylated corona to extend blood circulation, the nanostructures for large tumor accumulation by EPR, enzyme-sensitivity to enhance tumor penetration and cellular uptake, redox-active discharge for effective release of DOX, and lysosome acid-responding nucleus delivery of DOX. Simultaneously, several drug resistance pathways were restrained by these nanoassemblies. Ultimately, the nanoassemblies were found 
a

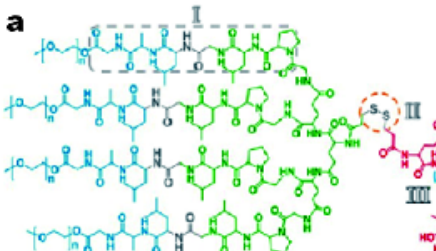

Dendrimeric Prodrugs

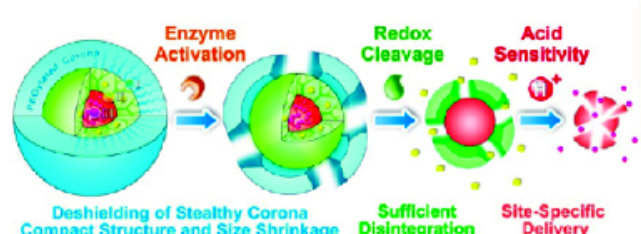
Delivery

Tumor Multiple Activated Dendrimeric Nanoassemblies

I GPLGLAG Pepticio II Disulfide Linkage IIII Hydrazone Bond

- Doxorubicin

\% MMPs

a. Long Blood Circulation

e. Cellular Uptake

g. Acid-Responsive Release
Lonidarnine

GSH

b. Passive Targeting

. Tumor Penetration

f. Cytoplasmic Delivery

h. Nuclear Delivery

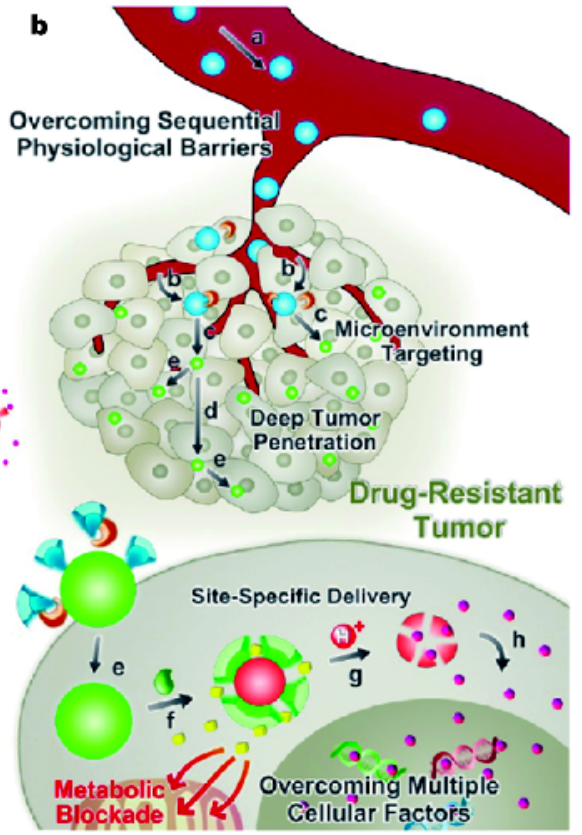

Figure 3 Schematic illustrations of (a) molecular and supramolecular engineering on tumor-specific multiple stimuli activated dendrimeric nanoassemblies with metabolic blockade and (b) their synergistic effects for overcoming physiological barriers and cellular factors of chemotherapy resistance. Reprinted from Ref. [106]. Copyright 2017, the American Chemical Society.

to inhibit $84 \%$ drug-resistant MCF-7R tumor in vivo, compared to $32 \%$ tumor growth inhibition accomplished by free $\mathrm{DOX} \cdot \mathrm{HCl}$ treatment.

\section{Dendrimer nanohybrid carriers in chemotherapy}

Dendrimer and other nano-vehicles-based hybrid carrier is another strategy for drug delivery [107]. Compared to some conventional nanocarriers, dendrimers have a smaller size, which can be easily loaded or conjugated to construct nanohybrid carriers with enhanced antitumor efficiency. Conventional NPs could make for accumulation at tumor tissue depending on the EPR effect, but they have poor deep penetration capacity into tumor tissues for uniform distribution. Fan and coworkers [108] designed a multistage nanocarrier by anti-tumor model drug methotrexate (MTX) loaded on PAMAM dendrimers encapsulated in gelatin NPs. This nanohybrid carrier was stable during systemic circulation and largely accumulated in tumor tissue via EPR effect. In the tumor microenvironment, PAMAM dendrimers were released from these nanohybrid carriers in response to MMP-2 enzymes and penetrated deeply into tumor tissue due to smaller size. Sun and coworkers [109] thought the synergistic effect between the components of nanocarriers with various functions could enable them to complete the circulation-accumulation-internalization-penetration-re- lease (CAPIR) cascade and achieve high therapeutic efficacy, and thus they designed nanohybrid carriers using DOX loaded PAMAM dendrimers encapsulated in liposome (Fig. 4). These nanohybrid carriers could complete the role of prolonging blood circulation and enhance tumor accumulation, while its "bomblets", DOX loaded PAMAM dendrimers with smaller size $(<5 \mathrm{~nm})$ complete the task of tumor penetration and cell internalization. Remarkably, the nanohybrid carriers could overcome the membrane-associated drug resistance and uptake DOX into drug-resistant cell. Ultimately, in-vivo therapeutic efficacy of the nanohybrid carrier had 85\% tumor inhibition rate in drug-resistant MCF-7 tumor.

\section{Dendrimers with inherent activity in chemotherapy}

Recently, therapeutic dendrimers as a new type of efficient chemotherapy drugs have been reported. Zhang and coworkers [110] designed the bioinspired tryptophanrich peptide dendrimers (TRPDs) as a chemotherapy drug for efficient tumor treatment (Fig. 5a). The tryptophan-rich dendrimeric structures of TRPDs significantly induced supramolecular interactions with DNA. Most importantly, TRPDs showed excellent cytotoxicity against various tumor cells by strong membrane permeability and prominently disturbed the cell cycle. Further experiment showed that the TRPDs also restrained the proliferation 

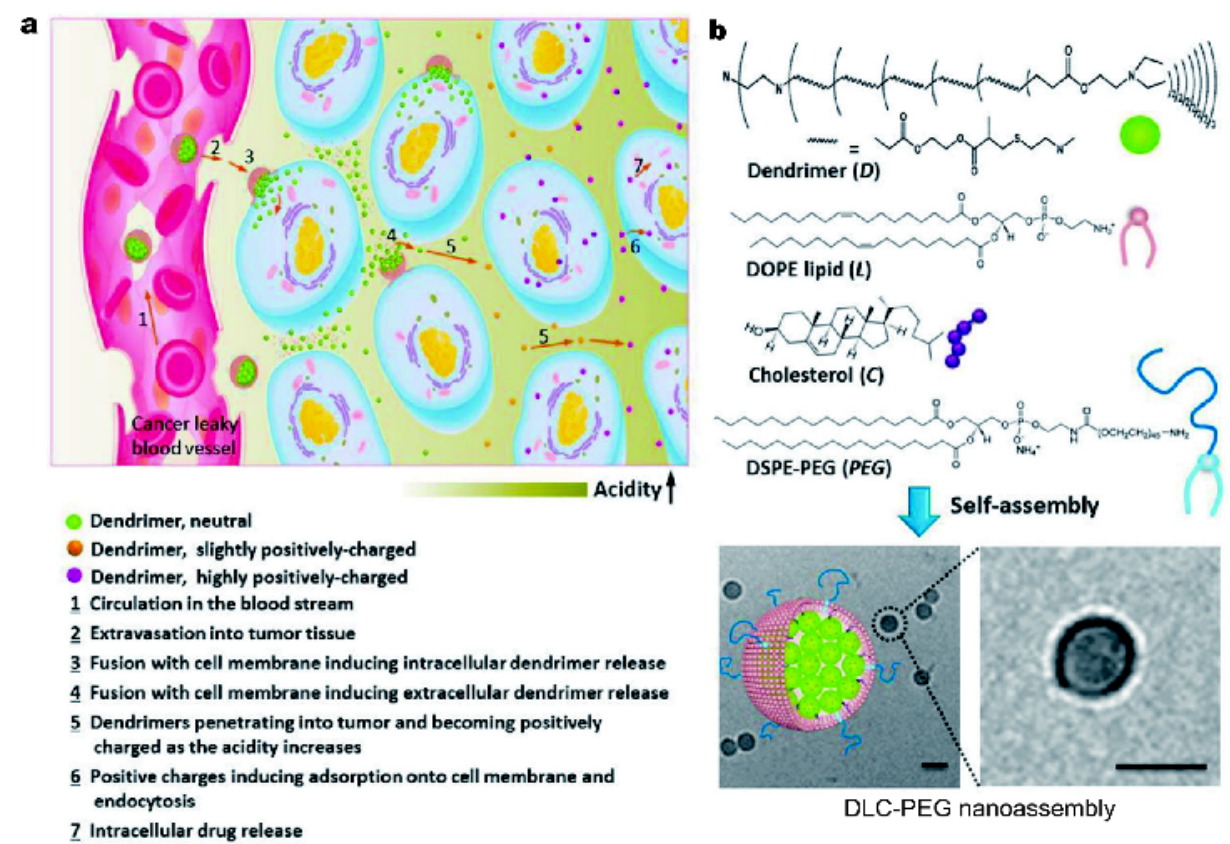

Figure 4 (a) Schematic of the cluster-bomb-like nanoassembly and how it accomplishes the CAPIR cascade. (b) The nanoassembly structure: the dendrimers were self-assembled with DOPE and DSPE-PEG lipids as well as cholesterol to form the nanoassembly with a dendrimer core and lipidic shell, which was confirmed by cryo-TEM imaging. Scale bar = $50 \mathrm{~nm}$. Reprinted from Ref [109]. Copyright 2014, WILEY-VCH.
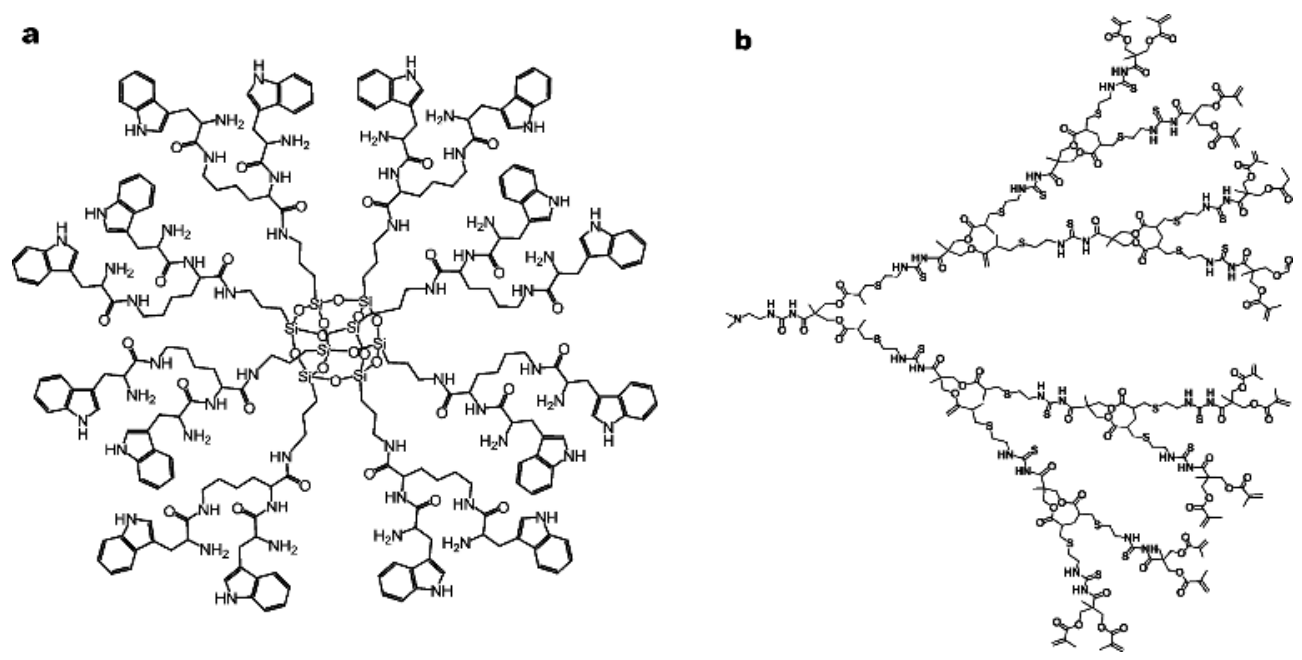

Figure 5 (a) Chemical structures of the TRPDs and (b) G4 PATU dendrimer.

and boosted apoptosis of cancer cell in vivo. Shao and coworkers [111] reported a polyacylthiourea dendrimer G4 polyacylthiourea (PATU), which had inherent potent anticancer activity and the absence of cytotoxicity in mice (Fig. 5b). The anticancer activity of G4 PATU in vivo was from the exhaust of bioavailable copper, the subsequent suppression of angiogenesis and cell proliferation. Remarkably, compared to DOX, this dendrimer could effi- ciently inhibit multidrug resistance (MDR) and tumor metastasis, with no-cytotoxin induced side effects.

\section{GENE THERAPY}

Gene therapy is a promising option for the treatment of cancers [112-114]. However, few safe and efficient gene vectors for the delivery of DNA and siRNA limit the development of clinical gene therapy. Cationic den- 
drimers, which possess cationic groups on the surface and peripheral multivalency, can bind nucleic acids for efficient condensation and intracellular delivery $[45,46]$.

\section{Traditional dendrimer/nucleic acid complexes in gene therapy}

The definite number of amine groups on the surface of dendrimer can efficiently condense DNA or siRNA into nanocarriers (dendriplexes) by electrostatic interaction and avoid their degradation by enzymes [115-118]. Then, the formed nanocarriers can be internalized into cells and localized in endosomes or lysosomes. In addition, plenty of tertiary amine groups of dendrimers can facilitate the endosomal escape of dendriplexes via a "proton-sponge" mechanism $[115,119,120]$. Up to now, PAMAM $[15,16]$, PPI [17], and PLL [121,122], were among the most-researched traditional dendrimers in gene delivery [20,70,123-129]. Haensler and coworkers [130] first reported that PAMAM dendrimers as non-viral gene vectors could efficiently express luciferase in cultured cell and found that Generation 6 (G6) PAMAM dendrimer had maximal gene transfection efficiency among G1 to G10 PAMAM dendrimers. Different generations of dendritic PLL were synthesized by Luo and colleagues, they found that G5 PLL complexes with plasmid DNAs showed the higher gene transfection than other dendrimers similar to PEI, but with lower cytotoxicity [131]. Disulfide cross-linked low generation (G2) PAMAM dendrimers were constructed as highly efficient gene carriers, which could avoid high cost and serious cytotoxicity of high generation dendrimers [132]. Cationic dendrimers are not only able to effectively deliver plasmid DNA but also siRNA to silence the heat shock protein 27 , resulting in a prominent anticancer effect in prostate cancer model $[133,134]$.

\section{Dendrimer conjugates in gene therapy}

The effects of traditional dendrimers in gene transfection are not desirable, which are usually blocked by poor transfection efficacy and serious cytotoxicity [45]. Modifying dendrimers with various functional groups or introducing degradable linkages by stimuli-cleavable bonds to construct dendrimer conjugates for gene delivery may be a promising task to improve gene transfection effect.

Dendrimers modified with alkaline amino acid (such as arginine, histidine and lysine) can improve the transfection efficacy (Fig. 6). Positively charged groups in alkaline amino acid can evidently increase the charge density of dendrimer surface, which is beneficial for DNA condensation and polyplex stability [135]. Guanidinium
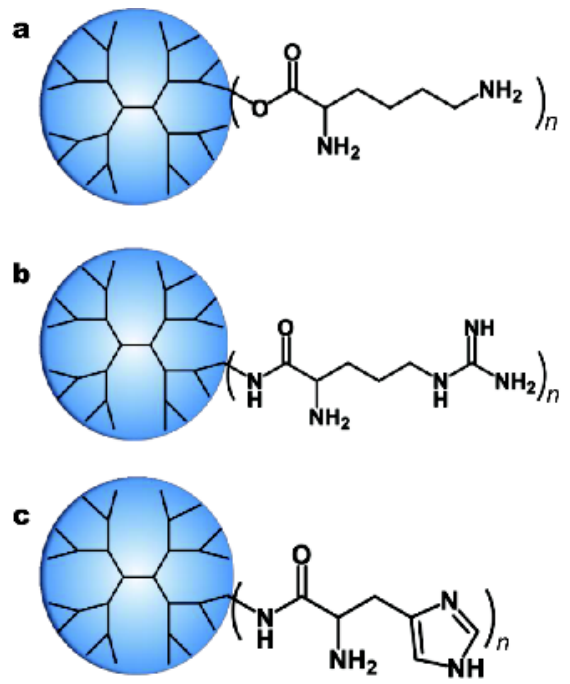

Figure 6 (a) Lysine, (b) arginine and (c) histidine modified dendrimers.

group of arginine shows stronger interaction with phosphates in DNA and cell membrane [136,137]. Histidine modified dendrimer can improve endosomal escape and the serum-resistance resulting from the imidazole group in the structure [138]. As a result, alkaline amino acidmodified dendrimer conjugates were widely used as efficient vectors for DNA and siRNA during the past decade $[131,139-160]$.

Cancer cell-specific receptor modified dendrimer conjugate can achieve the targeted gene delivery via ligandreceptor or antibody-antigen interaction. For example, epidermal growth factor receptors (EGFR) modified dendrimer conjugate can increase transfection efficiency of pDNA in liver cells 10-fold compared to the unmodified ones [161]. Antibody anti-CD71-modified PAMAM dendrimer shows much higher cellular uptake and more efficient antiapoptotic gene silencing in prostate cancer cells compared to no-antibody ones [162]. Transferrin-conjugated dendrimers can highly express tumor necrosis factor $\alpha(\mathrm{TNF} \alpha)$ by delivery of plasmids in prostate cancer cells in vitro and in vivo [163]. Major histocompatibility complex (MHC) class II-targeting peptides modified dendrimers can deliver DNA-based vaccines to specifically accumulate in professional antigen-presenting cells, which enhances immunostimulatory potency and provides an immunotherapy for tumor treatment [164].

Dendrimers modified with acid-responsive groups can also increase the transfection efficacy. Shen and coworkers [165] constructed acid active peptide pHLIP-conjugated PLL dendrimer to inhibit tumor growth by 
enhanced expression of siRNA targeting vascular endothelial growth factor. This dendrimer conjugate can weakly interact with cell membrane in physiological environment, whereas it can enhance gene internalization via a transmembrane $\alpha$-helix forming from $\mathrm{pHLIP}$ at tumor acidic microenvironments (Fig. 7). Benns and colleagues [166] developed a $\mathrm{pH}$-sensitive dendrimer conjugate PLH-g-PLL, which improved transfection by excellent membrane fusion at endosomal $\mathrm{pH}$ values and enhanced endosomal release of DNA.

Dendrimer conjugates containing disulfide bonds as gene carriers can improve the transfection efficacy. The spermine groups are conjugated to the dendritic scaffold of dendrimer via a disulfide linkage, which can easily be discharged by intracellular GSH. Owing to the weak affinity towards DNA of spermine groups, these reductionresponsive carriers show a controlled release of spermine groups and DNA [167]. Introducing disulfide bonds between dendrimer and a cell-binding ligand also can improve transfection effect. The ligand can enhance complex accumulation in the target cell, and further the carriers can release nucleic acids in an intracellular reduction-responsive manner [168].

\section{Amphiphilic dendrimers in gene therapy}

Amphiphilic dendrimers with hydrophilic and hydrophobic domains are able to form multivalent delivery systems for gene therapy. Lipid compounds such as fatty acids and cholesterol are always chosen as the hydrophobic parts. Lipids have strong fusogenic activity, which can improve cellular uptake and endosomal escape of polyplexes for effective transfection [169]. Amphiphilic dendrimers show the combined advantages of lipid and dendrimer for high-efficiency and safe gene delivery, which can be constructed by conjugation of lipids to the core or surface of dendrimer.

In general, high generation dendrimers with the high density positive charges facilitate the stability and inter- nalization of polyplexes into cells [115]. However, extra positive charges of polyplex may induce increased cytotoxicity [170]. Amphiphiles formed from conjugation of lipids to the core of low-generation dendrons, can selfassemble into micelles for safe and efficient gene delivery. In the early stages, PLL modifed with three dodecanoyl chains can achieve self-assembly and effective gene delivery (Fig. 8a) [171]. Yu and colleagues [172] constructed a series of amphiphilic PAMAM dendrimers with various alkyl chain length and dendron structure as siRNA vectors. They found that the vector bearing a C18 alkyl chain and a PAMAM dendron with third-generation structure, was able to transport Hsp27 siRNA and induce significant gene silencing against a castration-resistant cancer (Fig. 8b). G1 PAMAM conjugated with two alkyl chains such as unsaturated octadecyl (DL-G1-2C18) (Fig. 8c) and saturated octadecenyl (DL-G1-2C18-U2) (Fig. 8d) show much improved gene transfection efficacy. Particular, DL-G1-2C18-U2 presents more efficient transfection on HeLa cells compared to DL-G1-2C18. The results indicate that the unsaturated chains for the amphiphilic dendrimers with excellent gene transfection are very important [173]. Amphiphilic dendrimers having the same octadecyl chains but different generation of dendron parts show different transfection activity (Fig. 8e) [174]. Multivalent amphiphiles, which have a C18 alkyl chain in the core and a second-generation dendrimer (G2-octaamine, 4) with four glycine arrays on the surface, can be a safe and efficient carrier to transport siRNA and acquire effective gene silencing in HeLa cells (Fig. 8f) [175]. Selfassembling the defined arginine-containing amphiphilic dendritic lipopeptides for virus-inspired nanocarriers can greatly enhance transfection efficiency and reduce cytotoxicity in HepG2 cells (Fig. 8g) [176].

Conjugation of lipids to the periphery of dendrimer can also improve the efficacy of transfection. PAMAM dendrimers conjugated with different length alkyl chains can achieve efficient DNA delivery. The presence of alkyl
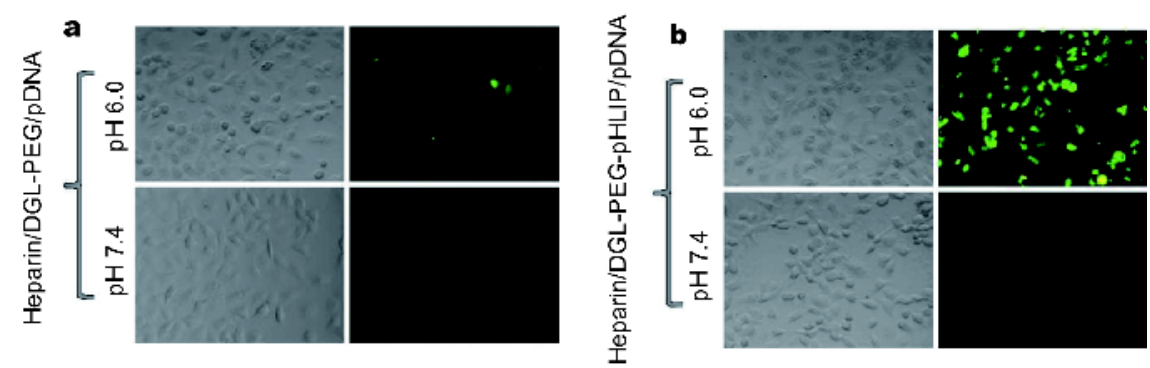

Figure 7 Liver cancer cells were treated with (a) nonmodified or (b) pHLIP conjugated PLL NPs at pH 6.0 (for representing tumor acidic pH environments and solid tumor cells) or pH 7.4 for $30 \mathrm{~min}$. Reprinted from Ref. [165]. Copyright 2013, WILEY-VCH. 

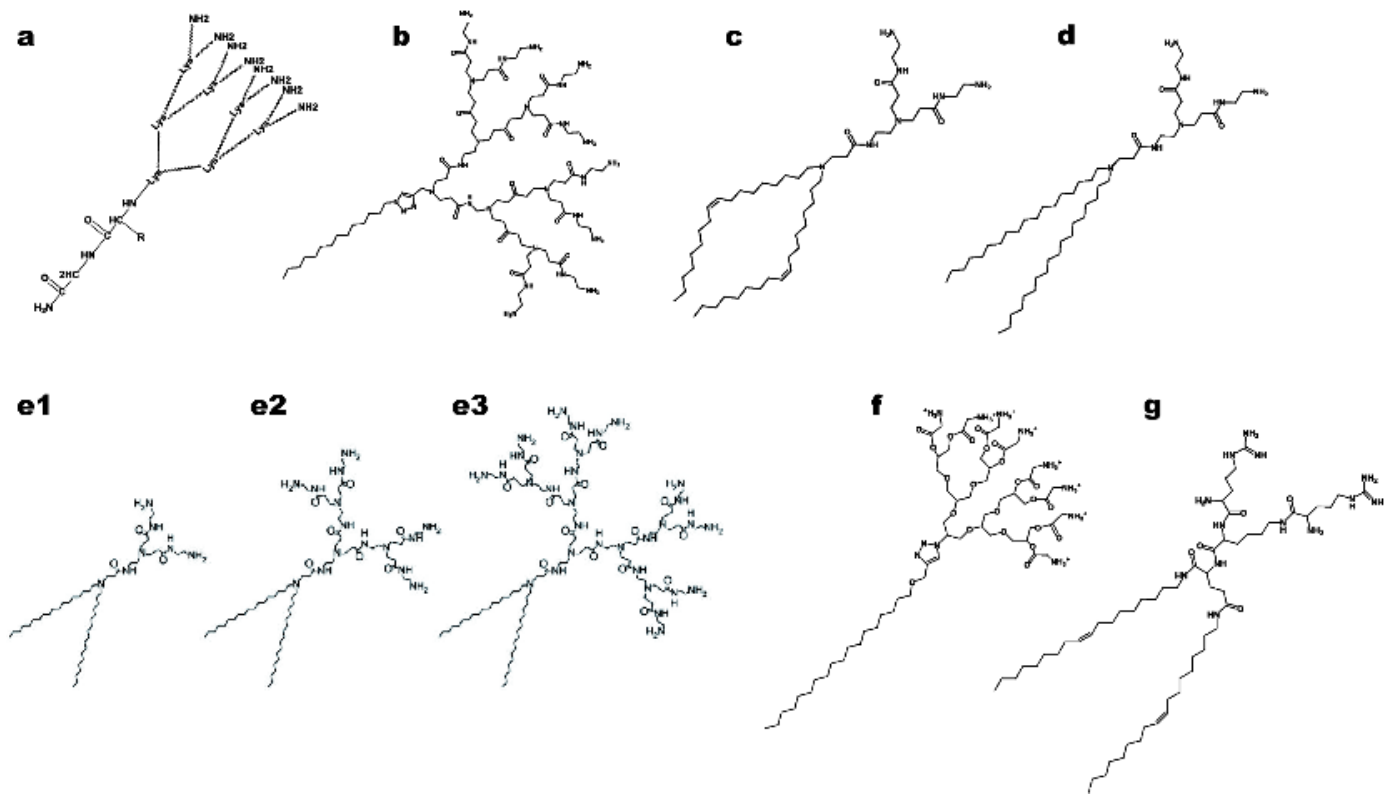

Figure 8 Structures of dendrimer-bearing lipids.

chains obviously increases the cellular uptake of polyplexes and the effect is positively correlated with the length. However, the smallest hydrophobic chains show the higher efficiency due to effortless DNA release. Similarly, PPI dendrimer modified with alkyl chains of suitable length increases 60 -fold transfection efficiency than the unmodified one [177]. Cholesterol and alkyl chains modified G2 PAMAM dendrimers are also benefit for gene transport, including excellent low cytotoxicity, serum-resistance, and efficient transfection. Among these dendrimers, G2 PAMAM dendrimer modified with a saturated C18 alkyl chain exhibits the highest transfection efficacy [178].

Stimuli-responsive amphiphilic dendrimers can be designed for effective gene delivery. Tschiche and coworkers [179] designed an amphiphilic dendrimer, which is composed of a lipoic acid-derived dendron structure and had the ability to self-assemble into supramolecular nanostructure. The redox-triggered disassembly leads to faster siRNA release and higher transfection efficiencies for gene silencing compared to noncrosslinked ones. Similarly, conjugating a disulfide bond to the surface of the core lipid-functionalized PLL dendrimer results in highefficiency RNA interference and low toxicity in vivo [180]. Recently, Liu and coworkers [181] proposed an amphiphilic dendrimer bola4A, which introduces a reactive oxygen species (ROS)-activatable thioacetal group in hydrophobic part and two PAMAM dendrons as the peripheral groups. Bola4A could compact siRNA into nanostructure to enhance cellular uptake and efficiently disassemble under the response of the built-in thioacetal linker in ROS-rich tumor cells for effective gene delivery and silencing.

\section{Dendrimer nanohybrid carriers in gene therapy}

Dendrimer nanohybrid carriers, which are constructed by dendrimer grafting onto NPs, such as quantum dots, carbon nanotubes, magnetic NPs, gold NPs, are widely used in gene delivery with enhanced transfection efficiency and reduced cytotoxicity compared to unmodified ones.

For example, $\mathrm{Xu}$ and coworkers [182] designed a functionalized low generation peptide dendrimer, which could self-assemble onto the surface of quantum dots to prepare multifunctional supramolecular hybrid dendrimers. These hybrid dendrimers show 50,000-fold higher gene transfection efficiency than single low generation peptide dendrimer and real-time tumor fluorescent signaling properties (Fig. 9a).

PAMAM dendrimers are grafted onto gold nanorods for delivering short hairpin RNA (shRNA) into breast cancer cells (Fig. 9b). These conjugates also can be used to kill cancer cells by synergetic photothermal ablation role via NIR light irradiation [183]. In addition, PAMAM dendrimers encapsulating gold NPs also exhibits much improved gene transfection efficacy and reduced cyto- 

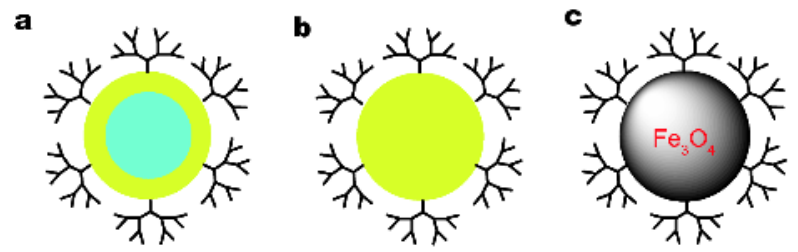

Figure 9 Structures of nanoparticle-modified dendrimers. (a) Dendrimer-conjugated quantum dot, (b) dendrimer-conjugated gold nanoparticle, and (c) dendrimer-conjugated $\mathrm{Fe}_{3} \mathrm{O}_{4}$.

toxicity on several cancer cells [184-187].

$\mathrm{Fe}_{3} \mathrm{O}_{4}$ nano-worm is modified with PAMAM dendrimers and utilized for siRNA delivery (Fig. 9c), which obviously promotes endosomal escape and suppresses the EGFR protein expression in glioblastoma in vivo [188]. Similarly, ternary magnetoplexes polyplexes containing PAMAM dendrimer-modified magnetic iron oxide greatly improve the transfection efficiency [189].

\section{CONCLUSIONS AND PERSPECTIVES}

Dendrimer-based NPs are emerging as a promising delivery system in cancer chemotherapy and gene therapy due to their well-defined nano size, 3D hyperbranched structure, and globular architecture. The dendritic scaffolds provide hydrophobic interior to load drug, while the periphery can link multifunctional surface groups for diverse applications. The unique features of tumor microenvironment also can be used to explore the active targeting or stimuli-responsive dendrimer based NPs to enhance therapeutic effect and reduce the toxic effect. There are several structures usually adopted in the design of dendrimer-based delivery systems, such as non-modified dendrimers, dendrimer conjugates, assembled amphiphilic dendrimers, nanohybrid dendrimer carriers and dendrimers with inherent activity. Although dendrimerbased NPs are effective against some cancers by single chemotherapy or gene therapy, the successful anticancer treatment is frequently impeded by MDR or tumor metastasis. Therefore, to take full advantage of dendrimers to develop the various combinations of chemotherapy and gene therapy, successful antitumor therapy may be achieved by overcoming MDR and inhibiting tumor metastasis. In addition, despite the numerous advantages of dendrimers as drug/gene carriers, most of them are limited by the implementation of concept and high cost for clinical applications. Therefore, researchers should pay attention to the complexity of in vivo environments and monitoring cost to reduce these problems and ensure clinical usefulness.
Received 6 February 2018; accepted 5 March 2018; published online 11 April 2018

1 Wilhelm S, Tavares AJ, Dai Q, et al. Analysis of nanoparticle delivery to tumours. Nat Rev Mater, 2016, 1: 16014

2 Yang K, Feng L, Liu Z. Stimuli responsive drug delivery systems based on nano-graphene for cancer therapy. Adv Drug Deliver Rev, 2016, 105: 228-241

3 El-Aneed A. An overview of current delivery systems in cancer gene therapy. J Control Release, 2004, 94: 1-14

4 Husain SR, Han J, Au P, et al. Gene therapy for cancer: regulatory considerations for approval. Cancer Gene Ther, 2015, 22: 554563

5 Jiang L, Li L, He X, et al. Overcoming drug-resistant lung cancer by paclitaxel loaded dual-functional liposomes with mitochondria targeting and pH-response. Biomaterials, 2015, 52: 126-139

6 Yao X, Zhu Q, Li C, et al. Carbamoylmannose enhances the tumor targeting ability of supramolecular NPs formed through host-guest complexation of a pair of homopolymers. J Mater Chem B, 2017, 5: 834-848

7 Arias JL. Drug targeting strategies in cancer treatment: An overview. Mini Rev Med Chem, 2011, 11: 1-17

8 Mohanty C, Das M, R. Kanwar J, et al. Receptor mediated tumor targeting: an emerging approach for cancer therapy. Curr Drug Deliv, 2011, 8: 45-58

9 Xu P, Van Kirk EA, Zhan Y, et al. Targeted charge-reversal NPs for nuclear drug delivery. Angew Chem Int Ed, 2007, 46: 49995002

10 Hubbell JA, Chilkoti A. Nanomaterials for drug delivery. Science, 2012, 337: 303-305

11 Chandra S, Barick KC, Bahadur D. Oxide and hybrid nanostructures for therapeutic applications. Adv Drug Deliver Rev, 2011, 63: 1267-1281

12 Lee SJ, Min HS, Ku SH, et al. Tumor-targeting glycol chitosan NPs as a platform delivery carrier in cancer diagnosis and therapy. Nanomedicine, 2014, 9: 1697-1713

13 Brigger I, Dubernet C, Couvreur P. NPs in cancer therapy and diagnosis. Adv Drug Deliver Rev, 2002, 54: 631-651

14 Zhang Y, Chen W, Yang C, et al. Enhancing tumor penetration and targeting using size-minimized and zwitterionic nanomedicines. J Control Release, 2016, 237: 115-124

15 Gérard HC, Mishra MK, Mao G, et al. Dendrimer-enabled DNA delivery and transformation of Chlamydia pneumoniae. Nanomed-Nanotechnol Biol Med, 2013, 9: 996-1008

16 Conti DS, Brewer D, Grashik J, et al. Poly(amidoamine) dendrimer nanocarriers and their aerosol formulations for siRNA delivery to the lung epithelium. Mol Pharm, 2014, 11: 1808-1822

17 Chisholm EJ, Vassaux G, Martin-Duque P, et al. Cancer-specific transgene expression mediated by systemic injection of NPs. Cancer Res, 2009, 69: 2655-2662

18 Merkel OM, Mintzer MA, Librizzi D, et al. Triazine dendrimers as nonviral vectors for in vitro and in vivo RNAi: The effects of peripheral groups and core structure on biological activity. Mol Pharm, 2010, 7: 969-983

19 Merkel OM, Mintzer MA, Sitterberg J, et al. Triazine dendrimers as nonviral gene delivery systems: effects of molecular structure on biological activity. Bioconjugate Chem, 2009, 20: 1799-1806

20 Lakshminarayanan A, Ravi VK, Tatineni R, et al. Efficient dendrimer-DNA complexation and gene delivery vector properties 
of nitrogen-core poly(propyl ether imine) dendrimer in mammalian cells. Bioconjugate Chem, 2013, 24: 1612-1623

21 Thankappan UP, Madhusudana SN, Desai A, et al. Dendritic poly (ether imine) based gene delivery vector. Bioconjugate Chem, 2011, 22: 115-119

22 Madhusudana SN, Padinjaremattathil Thankappan U, Desai A, et al. Enhancement of immunogenicity and efficacy of a plasmid DNA rabies vaccine by nanoformulation with a fourth-generation amine-terminated poly(ether imine) dendrimer. Int J Nanomed, 2014, 627

23 Perisé-Barrios AJ, Jiménez JL, Domínguez-Soto A, et al. Carbosilane dendrimers as gene delivery agents for the treatment of HIV infection. J Control Release, 2014, 184: 51-57

24 Li J, Lepadatu AM, Zhu Y, et al. Examination of structure-activity relationship of viologen-based dendrimers as CXCR4 antagonists and gene carriers. Bioconjugate Chem, 2014, 25: 907-917

25 Ferenc M, Pedziwiatr-Werbicka E, Nowak KE, et al. Phosphorus dendrimers as carriers of siRNA-characterisation of dendriplexes. Molecules, 2013, 18: 4451-4466

26 Maksimenko AV, Mandrouguine V, Gottikh MB, et al. Optimisation of dendrimer-mediated gene transfer by anionic oligomers. J Gene Med, 2003, 5: 61-71

27 Shcharbin D, Dzmitruk V, Shakhbazau A, et al. Fourth generation phosphorus-containing dendrimers: prospective drug and gene delivery carrier. Pharmaceutics, 2011, 3: 458-473

28 Mintzer MA, Grinstaff MW. Biomedical applications of dendrimers: a tutorial. Chem Soc Rev, 2011, 40: 173-190

29 Guo R, Shi X. Dendrimers in cancer therapeutics and diagnosis. Curr Drug Metab, 2012, 13: 1097-1109

30 Shen M, Shi X. Dendrimer-based organic/inorganic hybrid NPs in biomedical applications. Nanoscale, 2010, 2: 1596-1610

31 Zheng L, Zhu J, Shen M, et al. Targeted cancer cell inhibition using multifunctional dendrimer-entrapped gold NPs. MedChemComm, 2013, 4: 1001-1005

32 Svenson S, Tomalia DA. Dendrimers in biomedical applications -reflections on the field. Adv Drug Deliver Rev, 2005, 57: 21062129

33 Medina SH, El-Sayed MEH. Dendrimers as carriers for delivery of chemotherapeutic agents. Chem Rev, 2009, 109: 3141-3157

34 Medina SH, Tekumalla V, Chevliakov MV, et al. n-Acetylgalactosamine-functionalized dendrimers as hepatic cancer celltargeted carriers. Biomaterials, 2011, 32: 4118-4129

35 Uehara T, Ishii D, Uemura T, et al. $\gamma$-Glutamyl PAMAM dendrimer as versatile precursor for dendrimer-based targeting devices. Bioconjugate Chem, 2010, 21: 175-181

36 Ortiz Mellet C, Benito JM, García Fernández JM. Preorganized, macromolecular, gene-delivery systems. Chem Eur J, 2010, 16: 6728-6742

37 Li Y, Lai Y, Xu X, et al. Capsid-like supramolecular dendritic systems as $\mathrm{pH}$-responsive nanocarriers for drug penetration and site-specific delivery. Nanomed-Nanotechnol Biol Med, 2016, 12: 355-364

38 Wu W, Driessen W, Jiang X. Oligo(ethylene glycol)-based thermosensitive dendrimers and their tumor accumulation and penetration. J Am Chem Soc, 2014, 136: 3145-3155

39 Caminade AM, Ouali A, Laurent R, et al. The dendritic effect illustrated with phosphorus dendrimers. Chem Soc Rev, 2015, 44: 3890-3899

40 Ganesh T. Improved biochemical strategies for targeted delivery of taxoids. Bioorg Medicinal Chem, 2007, 15: 3597-3623
41 Cheng Y, Zhao L, Li Y, et al. Design of biocompatible dendrimers for cancer diagnosis and therapy: current status and future perspectives. Chem Soc Rev, 2011, 40: 2673-2703

42 Sailapu SK, Chattopadhyay A. Induction of electromotive force by an autonomously moving magnetic bot. Angew Chem Int Ed, 2014, 53: 1521-1524

43 Jia CJ, Liu Y, Bongard $\mathrm{H}$, et al. Very low temperature CO oxidation over colloidally deposited gold NPs on $\mathrm{Mg}(\mathrm{OH})_{2}$ and MgO. J Am Chem Soc, 2010, 132: 1520-1522

44 Moscariello $\mathrm{P}, \mathrm{Ng} \mathrm{DYW}$, Jansen $\mathrm{M}$, et al. Brain delivery of multifunctional dendrimer protein bioconjugates. Adv Sci, 2018, 1700897-1522

45 Wang M, Liu H, Li L, et al. A fluorinated dendrimer achieves excellent gene transfection efficacy at extremely low nitrogen to phosphorus ratios. Nat Commun, 2014, 5: 3053

46 Raghupathi KR, Guo J, Munkhbat O, et al. Supramolecular disassembly of facially amphiphilic dendrimer assemblies in response to physical, chemical, and biological stimuli. Acc Chem Res, 2014, 47: 2200-2211

47 Tian W, Ma Y. Theoretical and computational studies of dendrimers as delivery vectors. Chem Soc Rev, 2013, 42: 705-727

$48 \mathrm{Hu}$ J, Xu T, Cheng Y. NMR insights into dendrimer-based hostguest systems. Chem Rev, 2012, 112: 3856-3891

49 Jansen JFGA, de Brabander-van den Berg EMM, Meijer EW. Encapsulation of guest molecules into a dendritic box. Science, 1994, 266: 1226-1229

50 Jansen JFGA, Meijer EW, de Brabander-van den Berg EMM. The dendritic box: shape-selective liberation of encapsulated guests. J Am Chem Soc, 1995, 117: 4417-4418

51 Al-Jamal KT, Al-Jamal W'T, Wang JTW, et al. Cationic poly-1lysine dendrimer complexes doxorubicin and delays tumor growth in vitro and in vivo. ACS Nano, 2013, 7: 1905-1917

52 Fu F, Wu Y, Zhu J, et al. Multifunctional lactobionic acid-modified dendrimers for targeted drug delivery to liver cancer cells: investigating the role played by PEG spacer. ACS Appl Mater Interfaces, 2014, 6: 16416-16425

53 He X, Alves CS, Oliveira N, et al. RGD peptide-modified multifunctional dendrimer platform for drug encapsulation and targeted inhibition of cancer cells. Colloids Surfs B-Biointerfaces, 2015, 125: 82-89

54 Feng X, Cheng Y, Wu Q, et al. Stimuli response of cystamine-core dendrimer revealed by diffusion and NOE NMR studies. J Phys Chem B, 2011, 115: 3777-3783

$55 \mathrm{Hu} \mathrm{W}$, Cheng L, Cheng L, et al. Redox and pH-responsive poly (amidoamine) dendrimer-poly (ethylene glycol) conjugates with disulfide linkages for efficient intracellular drug release. Colloids Surfs B-Biointerfaces, 2014, 123: 254-263

56 Zhu J, Shi X. Dendrimer-based nanodevices for targeted drug delivery applications. J Mater Chem B, 2013, 1: 4199-4211

57 Zhu J, Zheng L, Wen S, et al. Targeted cancer theranostics using alpha-tocopheryl succinate-conjugated multifunctional dendrimer-entrapped gold NPs. Biomaterials, 2014, 35: 7635-7646

58 Zheng Y, Fu F, Zhang M, et al. Multifunctional dendrimers modified with alpha-tocopheryl succinate for targeted cancer therapy. Med Chem Commun, 2014, 5: 879-885

59 Zhu J, Fu F, Xiong Z, et al. Dendrimer-entrapped gold NPs modified with RGD peptide and alpha-tocopheryl succinate enable targeted theranostics of cancer cells. Colloids Surfs BBiointerfaces, 2015, 133: 36-42

60 She W, Luo K, Zhang C, et al. The potential of self-assembled, 
pH-responsive NPs of mPEGylated peptide dendron-doxorubicin conjugates for cancer therapy. Biomaterials, 2013, 34: 1613-1623

61 She W, Li N, Luo K, et al. Dendronized heparin-doxorubicin conjugate based nanoparticle as $\mathrm{pH}$-responsive drug delivery system for cancer therapy. Biomaterials, 2013, 34: 2252-2264

62 Li X, Takashima M, Yuba E, et al. PEGylated PAMAM dendrimer-doxorubicin conjugate-hybridized gold nanorod for combined photothermal-chemotherapy. Biomaterials, 2014, 35: 6576-6584

63 Lee CC, Gillies ER, Fox ME, et al. A single dose of doxorubicinfunctionalized bow-tie dendrimer cures mice bearing C-26 colon carcinomas. Proc Natl Acad Sci USA, 2006, 103: 16649-16654

64 Kono K, Kojima C, Hayashi N, et al. Preparation and cytotoxic activity of poly(ethylene glycol)-modified poly(amidoamine) dendrimers bearing adriamycin. Biomaterials, 2008, 29: 16641675

$65 \mathrm{Wu} \mathrm{S}$, Qi R, Kuang H, et al. pH-responsive drug delivery by amphiphilic copolymer through boronate-catechol complexation. ChemPlusChem, 2013, 78: 175-184

66 Jing B, Zhu Y. Disruption of supported lipid bilayers by semihydrophobic NPs. J Am Chem Soc, 2011, 133: 10983-10989

67 Zhang W, Tichy SE, Pérez LM, et al. Evaluation of multivalent dendrimers based on melamine: kinetics of thiol-disulfide exchange depends on the structure of the dendrimer. J Am Chem Soc, 2003, 125: 5086-5094

68 Hammer BAG, Baumgarten M, Müllen K. Covalent attachment and release of small molecules from functional polyphenylene dendrimers. Chem Commun, 2014, 50: 2034-2036

69 Brülisauer L, Kathriner N, Prenrecaj M, et al. Tracking the bioreduction of disulfide-containing cationic dendrimers. Angew Chem Int Ed, 2012, 51: 12454-12458

70 Peng SF, Su CJ, Wei MC, et al. Effects of the nanostructure of dendrimer/DNA complexes on their endocytosis and gene expression. Biomaterials, 2010, 31: 5660-5670

71 Lim J, Lo ST, Hill S, et al. Antitumor activity and molecular dynamics simulations of paclitaxel-laden triazine dendrimers. Mol Pharm, 2012, 9: 404-412

72 Lim J, Chouai A, Lo ST, et al. Design, synthesis, characterization, and biological evaluation of triazine dendrimers bearing paclitaxel using ester and ester/disulfide linkages. Bioconjugate Chem, 2009, 20: 2154-2161

73 Lee C, Lo ST, Lim J, et al. Design, synthesis and biological assessment of a triazine dendrimer with approximately 16 paclitaxel groups and 8 PEG groups. Mol Pharm, 2013, 10: 4452-4461

$74 \mathrm{Hu}$ Q, Katti PS, Gu Z. Enzyme-responsive nanomaterials for controlled drug delivery. Nanoscale, 2014, 6: 12273-12286

75 Lee SJ, Jeong YI, Park HK, et al. Enzyme-responsive doxorubicin release from dendrimer NPs for anticancer drug delivery. Int $\mathrm{J}$ Nanomed, 2015, 5489

76 Kojima C, Suehiro T, Watanabe K, et al. Doxorubicin-conjugated dendrimer/collagen hybrid gels for metastasis-associated drug delivery systems. Acta Biomater, 2013, 9: 5673-5680

77 Satsangi A, Roy SS, Satsangi RK, et al. Design of a paclitaxel prodrug conjugate for active targeting of an enzyme upregulated in breast cancer cells. Mol Pharm, 2014, 11: 1906-1918

78 Choi SK, Verma M, Silpe J, et al. A photochemical approach for controlled drug release in targeted drug delivery. Bioorg Medicinal Chem, 2012, 20: 1281-1290

79 Choi SK, Thomas TP, Li MH, et al. Photochemical release of methotrexate from folate receptor-targeting PAMAM dendrimer nanoconjugate. Photochem Photobiol Sci, 2012, 11: 653

80 Thota BNS, Urner LH, Haag R. Supramolecular architectures of dendritic amphiphiles in water. Chem Rev, 2016, 116: 2079-2102

81 Greig LM, Philp D. Applying biological principles to the assembly and selection of synthetic superstructures. Chem Soc Rev, 2001, 30: $287-302$

82 Jiang L, Chen W, Zhou S, et al. Dendritic phospholipid-based drug delivery systems. Biomater Sci, 2018, 491

$83 \mathrm{Hu}$ XY, Liu X, Zhang W, et al. Controllable construction of biocompatible supramolecular micelles and vesicles by watersoluble phosphate pillar[5, 6]arenes for selective anti-cancer drug delivery. Chem Mater, 2016, 28: 3778-3788

$84 \mathrm{Xu} \mathrm{X,} \mathrm{Li} \mathrm{Y,} \mathrm{Li} \mathrm{H,} \mathrm{et} \mathrm{al.} \mathrm{Smart} \mathrm{nanovehicles} \mathrm{based} \mathrm{on} \mathrm{pH}$-triggered disassembly of supramolecular peptide-amphiphiles for efficient intracellular drug delivery. Small, 2014, 10: 1133-1140

85 Wei T, Chen C, Liu J, et al. Anticancer drug nanomicelles formed by self-assembling amphiphilic dendrimer to combat cancer drug resistance. Proc Natl Acad Sci USA, 2015, 112: 2978-2983

86 Zhou T, Chen P, Niu L, et al. pH-responsive size-tunable selfassembled DNA dendrimers. Angew Chem Int Ed, 2012, 51: 11271-11274

87 Liu Y, Bryantsev VS, Diallo MS, et al. PAMAM dendrimers undergo $\mathrm{pH}$ responsive conformational changes without swelling. J Am Chem Soc, 2009, 131: 2798-2799

88 Li Y, Xiao W, Xiao K, et al. Well-defined, reversible boronate crosslinked nanocarriers for targeted drug delivery in response to acidic $\mathrm{pH}$ values and cis-diols. Angew Chem, 2012, 124: 29182923

89 Gillies ER, Jonsson TB, Fréchet JMJ. Stimuli-responsive supramolecular assemblies of linear-dendritic copolymers. J Am Chem Soc, 2004, 126: 11936-11943

90 Gillies ER, Fréchet JMJ. pH-responsive copolymer assemblies for controlled release of doxorubicin. Bioconjugate Chem, 2005, 16: 361-368

91 El Malah T, Ciesielski A, Piot L, et al. Conformationally preorganized and $\mathrm{pH}$-responsive flat dendrons: synthesis and selfassembly at the liquid-solid interface. Nanoscale, 2012, 4: 467472

92 Criscione JM, Le BL, Stern E, et al. Self-assembly of pH-responsive fluorinated dendrimer-based particulates for drug delivery and noninvasive imaging. Biomaterials, 2009, 30: 39463955

93 Chen L, Chen T, Fang W, et al. Synthesis and pH-responsive "schizophrenic" aggregation of a linear-dendron-like polyampholyte based on oppositely charged polypeptides. Biomacromolecules, 2013, 14: 4320-4330

94 She W, Pan D, Luo K, et al. PEGylated dendrimer-doxorubicin cojugates as $\mathrm{pH}$-sensitive drug delivery systems: synthesis and in vitro characterization. J Biomed nanotechnol, 2015, 11: 964-978

95 Takemoto H, Miyata K, Hattori S, et al. Acidic pH-responsive siRNA conjugate for reversible carrier stability and accelerated endosomal escape with reduced IFNa-associated immune response. Angew Chem, 2013, 125: 6338-6341

96 Li HJ, Du JZ, Du XJ, et al. Stimuli-responsive clustered NPs for improved tumor penetration and therapeutic efficacy. Proc Natl Acad Sci USA, 2016, 113: 4164-4169

97 Shao Y, Shi C, Xu G, et al. Photo and redox dual responsive reversibly cross-linked nanocarrier for efficient tumor-targeted drug delivery. ACS Appl Mater Interfaces, 2014, 6: 10381-10392 
98 Li Y, Li Y, Zhang X, et al. Supramolecular PEGylated dendritic systems as $\mathrm{pH} /$ redox dual-responsive theranostic nanoplatforms for platinum drug delivery and NIR imaging. Theranostics, 2016, 6: $1293-1305$

99 Zhang C, Pan D, Luo K, et al. Dendrimer-doxorubicin conjugate as enzyme-sensitive and polymeric nanoscale drug delivery vehicle for ovarian cancer therapy. Polym Chem, 2014, 5: 52275235

100 Zhang C, Pan D, Luo K, et al. Peptide dendrimer-doxorubicin conjugate-based NPs as an enzyme-responsive drug delivery system for cancer therapy. Adv Healthcare Mater, 2015, 3: 12991308

101 Li N, Li N, Yi Q, et al. Amphiphilic peptide dendritic copolymerdoxorubicin nanoscale conjugate self-assembled to enzyme-responsive anti-cancer agent. Biomaterials, 2014, 35: 9529-9545

102 Harnoy AJ, Rosenbaum I, Tirosh E, et al. Enzyme-responsive amphiphilic PEG-dendron hybrids and their assembly into smart micellar nanocarriers. J Am Chem Soc, 2014, 136: 7531-7534

103 Sun L, Ma X, Dong CM, et al. NIR-responsive and lectin-binding doxorubicin-loaded nanomedicine from Janus-type dendritic PAMAM amphiphiles. Biomacromolecules, 2012, 13: 3581-3591

104 Liu ZX, Feng Y, Zhao ZY, et al. A new class of dendritic metallogels with multiple stimuli-responsiveness and as templates for the in situ synthesis of silver NPs. Chem Eur J, 2014, 20: 533541

105 Huang $\mathrm{S}, \mathrm{Xu} \mathrm{Y}$, Xie M, et al. Synthesis of magnetic $\mathrm{CoFe}_{2} \mathrm{O}_{4} / \mathrm{g}$ $\mathrm{C}_{3} \mathrm{~N}_{4}$ composite and its enhancement of photocatalytic ability under visible-light. Colloids Surfs A-Physicochem Eng Aspects, 2015, 478: 71-80

106 Li Y, Xu X, Zhang X, et al. Tumor-specific multiple stimuliactivated dendrimeric nanoassemblies with metabolic blockade surmount chemotherapy resistance. ACS Nano, 2017, 11: 416429

107 Kesharwani P, Gothwal A, Iyer AK, et al. Dendrimer nanohybrid carrier systems: an expanding horizon for targeted drug and gene delivery. Drug Discovery Today, 2018, 23: 300-314

108 Fan Y, Yuan S, Huo MM, et al. Spatial controlled multistage nanocarriers through hybridization of dendrimers and gelatin NPs for deep penetration and therapy into tumor tissue. Nanomed-Nanotechnol Biol Med, 2017, 13: 1399-1410

109 Sun Q, Sun X, Ma X, et al. Integration of nanoassembly functions for an effective delivery cascade for cancer drugs. Adv Mater, 2014, 26: 7615-7621

110 Zhang X, Zhang Z, Xu X, et al. Bioinspired therapeutic dendrimers as efficient peptide drugs based on supramolecular interactions for tumor inhibition. Angew Chem Int Ed, 2015, 54: 4289-4294

111 Shao S, Zhou Q, Si J, et al. A non-cytotoxic dendrimer with innate and potent anticancer and anti-metastatic activities. Nat Biomed Eng, 2017, 1: 745-757

112 Naldini L. Gene therapy returns to centre stage. Nature, 2015, 526: $351-360$

113 Lai YH, Lin CC, Chen SH, et al. Tumor-specific suicide gene therapy for hepatocellular carcinoma by transcriptionally targeted retroviral replicating vectors. Gene Ther, 2015, 22: 155-162

114 Thomas CE, Ehrhardt A, Kay MA. Progress and problems with the use of viral vectors for gene therapy. Nat Rev Genet, 2003, 4: 346-358

115 Eichman JD, Bielinska AU, Kukowska-Latallo JF, et al. The use of PAMAM dendrimers in the efficient transfer of genetic material into cells. Pharmaceutical Sci Tech Today, 2000, 3: 232-245

116 Qamhieh K, Nylander T, Black CF, et al. Complexes formed between DNA and poly(amido amine) dendrimers of different generations - modelling DNA wrapping and penetration. Phys Chem Chem Phys, 2014, 16: 13112-13122

117 Pavan GM, Danani A, Pricl S, et al. Modeling the multivalent recognition between dendritic molecules and DNA: understanding how ligand "sacrifice" and screening can enhance binding. J Am Chem Soc, 2009, 131: 9686-9694

118 Shcharbin D, Pedziwiatr E, Bryszewska M. How to study dendriplexes I: Characterization. J Control Release, 2009, 135: 186197

119 Dufès C, Uchegbu IF, Schätzlein AG. Dendrimers in gene delivery. Adv Drug Deliver Rev, 2005, 57: 2177-2202

120 Yezhelyev MV, Qi L, O'Regan RM, et al. Proton-sponge coated quantum dots for siRNA delivery and intracellular imaging. J Am Chem Soc, 2008, 130: 9006-9012

121 Inoue $\mathrm{Y}$, Kurihara $\mathrm{R}$, Tsuchida $\mathrm{A}$, et al. Efficient delivery of siRNA using dendritic poly(l-lysine) for loss-of-function analysis. J Control Release, 2008, 126: 59-66

122 Ma D, Lin QM, Zhang LM, et al. A star-shaped porphyrin-arginine functionalized poly(l-lysine) copolymer for photo-enhanced drug and gene co-delivery. Biomaterials, 2014, 35: 4357-4367

123 Kukowska-Latallo JF, Bielinska AU, Johnson J, et al. Efficient transfer of genetic material into mammalian cells using starburst polyamidoamine dendrimers. Proc Natl Acad Sci USA, 1996, 93: 4897-4902

124 Santos JL, Oramas E, Pêgo AP, et al. Osteogenic differentiation of mesenchymal stem cells using PAMAM dendrimers as gene delivery vectors. J Control Release, 2009, 134: 141-148

125 Wang $\mathrm{P}$, Zhao XH, Wang ZY, et al. Generation 4 polyamidoamine dendrimers is a novel candidate of nano-carrier for gene delivery agents in breast cancer treatment. Cancer Lett, 2010, 298: 34-49

126 Dufès C, Keith WN, Bilsland A, et al. Synthetic anticancer gene medicine exploits intrinsic antitumor activity of cationic vector to cure established tumors. Cancer Res, 2005, 65: 8079-8084

127 Navarro G, Maiwald G, Haase R, et al. Low generation PAMAM dendrimer and $\mathrm{CpG}$ free plasmids allow targeted and extended transgene expression in tumors after systemic delivery. J Control Release, 2010, 146: 99-105

128 Chaplot SP, Rupenthal ID. Dendrimers for gene delivery-a potential approach for ocular therapy? J Pharm Pharmacol, 2014, 66: $542-556$

129 Shcharbin D, Shakhbazau A, Bryszewska M. Poly(amidoamine) dendrimer complexes as a platform for gene delivery. Expert Opin Drug Deliver, 2013, 10: 1687-1698

130 Haensler J, Szoka Jr. FC. Polyamidoamine cascade polymers mediate efficient transfection of cells in culture. Bioconjugate Chem, 1993, 4: 372-379

131 Luo K, Li C, Wang G, et al. Peptide dendrimers as efficient and biocompatible gene delivery vectors: Synthesis and in vitro characterization. J Control Release, 2011, 155: 77-87

132 Liu H, Wang H, Yang W, et al. Disulfide cross-linked low generation dendrimers with high gene transfection efficacy, low cytotoxicity, and low cost. J Am Chem Soc, 2012, 134: 17680-17687

133 Liu X, Liu C, Laurini E, et al. Efficient delivery of sticky siRNA and potent gene silencing in a prostate cancer model using a generation 5 triethanolamine-core PAMAM dendrimer. Mol Pharm, 2012, 9: 470-481 
134 Liu XX, Rocchi P, Qu FQ, et al. PAMAM dendrimers mediate siRNA delivery to target Hsp27 and produce potent antiproliferative effects on prostate cancer cells. ChemMedChem, 2009, 4: 1302-1310

135 Yang J, Liu Y, Wang $\mathrm{H}$, et al. The biocompatibility of fatty acid modified dextran-agmatine bioconjugate gene delivery vector. Biomaterials, 2012, 33: 604-613

136 Pantos A, Tsogas I, Paleos CM. Guanidinium group: A versatile moiety inducing transport and multicompartmentalization in complementary membranes. BioChim Biophysica Acta (BBA)Biomembranes, 2008, 1778: 811-823

137 Tabujew I, Freidel C, Krieg B, et al. The guanidinium group as a key part of water-soluble polymer carriers for siRNA complexation and protection against degradation. Macromol Rapid Commun, 2014, 35: 1191-1197

138 Wen Y, Guo Z, Du Z, et al. Serum tolerance and endosomal escape capacity of histidine-modified pDNA-loaded complexes based on polyamidoamine dendrimer derivatives. Biomaterials, 2012, 33: 8111-8121

139 Chang J, Xu X, Li H, et al. Components simulation of viral envelope via amino acid modified chitosans for efficient nucleic acid delivery: in vitro and in vivo study. Adv Funct Mater, 2013, 23: 2691-2699

140 Choi JS, Nam K, Park JY, et al. Enhanced transfection efficiency of PAMAM dendrimer by surface modification with $\mathrm{L}$-arginine. J Control Release, 2004, 99: 445-456

141 Nam HY, Nam K, Hahn HJ, et al. Biodegradable PAMAM ester for enhanced transfection efficiency with low cytotoxicity. Biomaterials, 2009, 30: 665-673

142 Sanclimens G, Shen H, Giralt E, et al. Synthesis and screening of a small library of proline-based biodendrimers for use as delivery agents. Biopolymers, 2010, 80: 800-814

143 Kim JB, Choi JS, Nam K, et al. Enhanced transfection of primary cortical cultures using arginine-grafted PAMAM dendrimer, PAMAM-Arg. J Control Release, 2006, 114: 110-117

144 Kim T, Baek J, Yoon JK, et al. Synthesis and characterization of a novel arginine-grafted dendritic block copolymer for gene delivery and study of its cellular uptake pathway leading to transfection. Bioconjugate Chem, 2007, 18: 309-317

145 Kim TI, Baek JU, Zhe Bai C, et al. Arginine-conjugated polypropylenimine dendrimer as a non-toxic and efficient gene delivery carrier. Biomaterials, 2007, 28: 2061-2067

146 Kim TI, Bai CZ, Nam K, et al. Comparison between arginine conjugated PAMAM dendrimers with structural diversity for gene delivery systems. J Control Release, 2009, 136: 132-139

147 Nam HY, Hahn HJ, Nam K, et al. Evaluation of generations 2, 3 and 4 arginine modified PAMAM dendrimers for gene delivery. Int J Pharm, 2008, 363: 199-205

148 How SE, Unciti-Broceta A, Sánchez-Martín RM, et al. Solid-phase synthesis of a lysine-capped bis-dendron with remarkable DNA delivery abilities. Org Biomol Chem, 2008, 6: 2266

149 Kim ID, Lim CM, Kim JB, et al. Neuroprotection by biodegradable PAMAM ester (e-PAM-R)-mediated HMGB1 siRNA delivery in primary cortical cultures and in the postischemic brain. J Control Release, 2010, 142: 422-430

150 Aldawsari H, Edrada-Ebel RA, Blatchford DR, et al. Enhanced gene expression in tumors after intravenous administration of arginine-, lysine- and leucine-bearing polypropylenimine polyplex. Biomaterials, 2011, 32: 5889-5899

151 Jang SH, Choi SJ, Oh JH, et al. Nonviral gene delivery to human ovarian cancer cells using arginine-grafted PAMAM dendrimer. Drug Dev Ind Pharm, 2011, 37: 41-46

152 Shah N, Steptoe RJ, Parekh HS. Low-generation asymmetric dendrimers exhibit minimal toxicity and effectively complex DNA. J Peptide Sci, 2011, 17: 470-478

153 Luo K, Li C, Li L, et al. Arginine functionalized peptide dendrimers as potential gene delivery vehicles. Biomaterials, 2012, 33: 4917-4927

154 Kim ID, Shin JH, Lee HK, et al. Intranasal delivery of HMGB1binding heptamer peptide confers a robust neuroprotection in the postischemic brain. NeuroSci Lett, 2012, 525: 179-183

155 Son SJ, Yu GS, Choe YH, et al. PAMAM dendrimers conjugated with $\mathrm{L}$-arginine and $\gamma$-aminobutyric acid as novel polymeric gene delivery carriers. Bull Korean Chem Soc, 2013, 34: 579-584

156 Liu C, Liu X, Rocchi P, et al. Arginine-terminated generation 4 PAMAM dendrimer as an effective nanovector for functional siRNA delivery in vitro and in vivo. Bioconjugate Chem, 2014, 25: 521-532

157 Bai CZ, Choi S, Nam K, et al. Arginine modified PAMAM dendrimer for interferon beta gene delivery to malignant glioma. Int J Pharm, 2013, 445: 79-87

158 Tziveleka LA, Psarra AMG, Tsiourvas D, et al. Synthesis and characterization of guanidinylated poly(propylene imine) dendrimers as gene transfection agents. J Control Release, 2007, 117: 137-146

159 Li YF, Morcos PA. Design and synthesis of dendritic molecular transporter that achieves efficient in vivo delivery of morpholino antisense oligo. Bioconjugate Chem, 2008, 19: 1464-1470

160 Chi B, Park SJ, Park MH, et al. Oligopeptide delivery carrier for osteoclast precursors. Bioconjugate Chem, 2010, 21: 1473-1478

$161 \mathrm{Yu} \mathrm{H}$, Nie Y, Dohmen C, et al. Epidermal growth factor-PEG functionalized PAMAM-pentaethylenehexamine dendron for targeted gene delivery produced by click chemistry. Biomacromolecules, 2011, 12: 2039-2047

162 Felber AE, Castagner B, Elsabahy M, et al. siRNA nanocarriers based on methacrylic acid copolymers. J Control Release, 2011, 152: $159-167$

163 Al Robaian M, Chiam KY, Blatchford DR, et al. Therapeutic efficacy of intravenously administered transferrin-conjugated dendriplexes on prostate carcinomas. Nanomedicine, 2014, 9: 421434

164 Daftarian P, Kaifer AE, Li W, et al. Peptide-conjugated PAMAM dendrimer as a universal DNA vaccine platform to target antigenpresenting cells. Cancer Res, 2011, 71: 7452-7462

165 Han L, Ma H, Guo Y, et al. pH-controlled delivery of NPs into tumor cells. Adv Healthcare Mater, 2013, 2: 1435-1439

166 Benns JM, Choi JS, Mahato RI, et al. pH-sensitive cationic polymer gene delivery vehicle: $N$-Ac-poly(L-histidine)-graft-poly (L-lysine) comb shaped polymer. Bioconjugate Chem, 2000, 11: 637-645

167 Kostiainen MA, Rosilo H. Low-molecular-weight dendrons for DNA binding and release by reduction-triggered degradation of multivalent interactions. Chem Eur J, 2009, 15: 5656-5660

168 Beloor J, Ramakrishna S, Nam K, et al. Effective gene delivery into human stem cells with a cell-targeting peptide-modified bioreducible polymer. Small, 2015, 11: 2069-2079

169 Liu Z, Zhang Z, Zhou C, et al. Hydrophobic modifications of cationic polymers for gene delivery. Prog Polymer Sci, 2010, 35: $1144-1162$

170 Mastrobattista E, Hennink WE. Charged for success. Nat Mater, 
2012, 11: 10-12

171 Wimmer N, Marano RJ, Kearns PS, et al. Syntheses of polycationic dendrimers on lipophilic peptide core for complexation and transport of oligonucleotides. Bioorg Medicinal Chem Lett, 2002, 12: 2635-2637

172 Yu T, Liu X, Bolcato-Bellemin AL, et al. An amphiphilic dendrimer for effective delivery of small interfering RNA and gene silencing in vitro and in vivo. Angew Chem Int Ed, 2012, 51: 8478-8484

173 Yuba E, Nakajima Y, Tsukamoto K, et al. Effect of unsaturated alkyl chains on transfection activity of poly(amidoamine) dendron-bearing lipids. J Control Release, 2012, 160: 552-560

174 Kono K, Ikeda R, Tsukamoto K, et al. Polyamidoamine dendronbearing lipids as a nonviral vector: influence of dendron generation. Bioconjugate Chem, 2012, 23: 871-879

175 Malhotra S, Bauer H, Tschiche A, et al. Glycine-terminated dendritic amphiphiles for nonviral gene delivery. Biomacromolecules, 2012, 13: 3087-3098

$176 \mathrm{Xu} \mathrm{X}$, Jiang Q, Zhang X, et al. Virus-inspired mimics: self-assembly of dendritic lipopeptides into arginine-rich nanovectors for improving gene delivery. J Mater Chem B, 2015, 3: 7006-7010

177 Hashemi M. Gene transfer enhancement by alkylcarboxylation of poly(propylenimine). Nanomedicine J, 2013, 1: 55-62

178 Morales-Sanfrutos J, Megia-Fernandez A, Hernandez-Mateo F, et al. Alkyl sulfonyl derivatized PAMAM-G2 dendrimers as nonviral gene delivery vectors with improved transfection efficiencies. Org Biomol Chem, 2011, 9: 851-864

179 Tschiche A, Thota BNS, Neumann F, et al. Crosslinked redoxresponsive micelles based on lipoic acid-derived amphiphiles for enhanced siRNA delivery. Macromol Biosci, 2016, 16: 811-823

180 Baigude H, Su J, McCarroll J, et al. In vivo delivery of RNAi by reducible interfering NPs (iNOPs). ACS Med Chem Lett, 2013, 4: 720-723

181 Liu X, Wang Y, Chen C, et al. A fluorinated bola-amphiphilic dendrimer for on-demand delivery of siRNA, via specific response to reactive oxygen species. Adv Funct Mater, 2016, 26:
8594-8603

182 Xu X, Jian Y, Li Y, et al. Bio-inspired supramolecular hybrid dendrimers self-assembled from low-generation peptide dendrons for highly efficient gene delivery and biological tracking. ACS Nano, 2014, 8: 9255-9264

183 Cui D, Huang P, Zhang C, et al. Dendrimer-modified gold nanorods as efficient controlled gene delivery system under nearinfrared light irradiation. J Control Release, 2011, 152: e137-e139

184 Kong L, Alves CS, Hou W, et al. RGD peptide-modified dendrimer-entrapped gold NPs enable highly efficient and specific gene delivery to stem cells. ACS Appl Mater Interfaces, 2015, 7: 4833-4843

185 Shan Y, Luo T, Peng C, et al. Gene delivery using dendrimerentrapped gold NPs as nonviral vectors. Biomaterials, 2012, 33: 3025-3035

186 Kim ST, Chompoosor A, Yeh YC, et al. Dendronized gold NPs for siRNA delivery. Small, 2012, 8: 3253-3256

187 Figueroa ER, Lin AY, Yan J, et al. Optimization of PAMAM-gold nanoparticle conjugation for gene therapy. Biomaterials, 2014, 35 : 1725-1734

188 Agrawal A, Min DH, Singh N, et al. Functional delivery of siRNA in mice using dendriworms. ACS Nano, 2009, 3: 2495-2504

189 Liu WM, Xue YN, He WT, et al. Dendrimer modified magnetic iron oxide nanoparticle/DNA/PEI ternary complexes: A novel strategy for magnetofection. J Control Release, 2011, 152: e159e160

Acknowledgements This work was supported by the National Natural Science Foundation of China (81601594, 51690153, 21474045 and 21720102005).

Author contributions Jiang L, Zhou S, Zhang X and Wu W wrote the paper; Jiang $\mathrm{L}$ and Jiang $\mathrm{X}$ designed the outlines.

Conflict of interest The authors declare that they have no conflict of interest. 

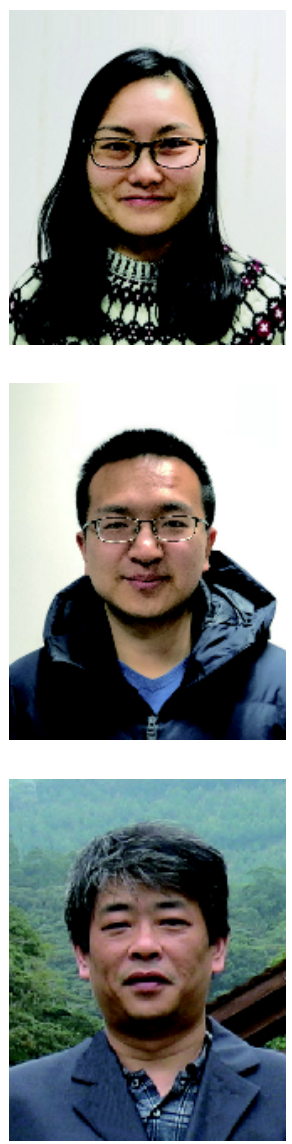

Lei Jiang is an assistant porfessor of the School of Pharmacy in China Pharmaceutical University. She received her PhD degree from Shenyang Pharmaceutical University. She was a postdoctoral fellow at MOE Key Laboratory of High Performance Polymer Materials and Technology, and the Department of Polymer Science \& Engineering, College of Chemistry \& Chemical Engineering in Nanjing University.

Sensen Zhou received his BSc degree in polymer science and engineering from Heifei University of Technology in 2015. Now, he is a $\mathrm{PhD}$ candidate at Nanjing University. His current research interests include the design of biomaterials in drug delivery and bioimaging.

Xiqun Jiang is a professor of MOE Key Laboratory of High Performance Polymer Materials and Technology, and the Department of Polymer Science \& Engineering, College of Chemistry \& Chemical Engineering in Nanjing University. He is the winner of the National Science Foundation for Distinguished Young Scholars of China.

\section{基于树状大分子纳米载体的化疗及基因治疗在肿瘤治疗中的应用}

姜雷 ${ }^{1,2}$, 周森森 ${ }^{1}$, 张小可 $^{1}$, 武伟 $^{1}$, 蒋锡群 ${ }^{*}$

摘要 针对肿瘤组织的微环境, 结合树状大分子的特点可以构建定向可控药物、基因传递系统, 实现化学或基因治疗中的高效低毒. 本综 述从树状大分子的结构出发, 总结了其纳米载体在肿瘤治疗中的最新进展, 尤其重点讨论了传统树状大分子、树状大分子偶联物、可自 组装的两亲性树状大分子、杂化树状大分子及自身具有药理活性的树状大分子作为药物或基因递送载体的应用. 我们希望本综述将有助 于启发未来的相关研究, 以进一步拓展这种材料在肿瘤治疗中的新应用. 